\title{
ENAMELLED STEEL SUBSTRATES FOR PRINTED CIRCUITS
}

\author{
R. KUŽEL and J. BROUKAL \\ Faculty of Mathematics and Physics, Charles University, Ke Karlovu 5, 12116 Prague 2 and State \\ Glass Research Institute, 50192 Hradec Králové I, Czechoslovakia
}

(Received November 11, 1981; in final form November 11, 1981)

The preparation of steel substrates coated with intermediate ground and final ceramic coatings is described. The basic material for the preparation of both coatings is the same kind of special glass. The coatings were thermally treated up to $960^{\circ} \mathrm{C}$. The resulting substrates were tested for the usage in thick film technology by applying ruthenium resistor compositions designed for use on ceramic substrates. The resistors were fired up to $900^{\circ} \mathrm{C}$ and their resistance and TCR were measured. They showed almost the same dependence on firing temperature as the resistors printed on alumina substrates. The TCR was only shifted towards more positive values.

\section{INTRODUCTION}

Papers presented by S.J. Stein and R.B. Schabacker at the European Hybrid Microelectronics Conference in Ghent (May 21-22-23, 1979) showed a rapid growth of interest in enamelled substrates. ${ }^{1,2}$ This interest is especially understandable due to the present trend in technology in hybrids being more and more centred on the use of non-precious metals, new substrate materials and new lower cost techniques.

In 1979 we succeeded in preparing protective coatings on steel ${ }^{3}$ with exceptional properties which could be presumed to be suitable for the preparation of insulated steel substrates, applicable for heat treatment up to temperatures above $800^{\circ} \mathrm{C}$. We tried to prepare new types of steel substrates coated with ceramic materials and to test them for the preparation of thick film resistors printed by means of ruthenium based systems designed for use on ceramic substrates.

\section{PREPARATION OF ENAMELLED STEEL SUBSTRATES}

\subsection{Intermediate ground coating}

The coating created on steel sheets by means of special glass marked EV 201 formed the ground for the preparation of substrates coated with a ceramic film. The composition of the respective glass is indicated in patent applications. ${ }^{3,4}$

The main preparation of the ground coating is as follows: finely ground glass frit is applied in a thin uniform film to a steel sheet by the method of electrostatic spraying or by simple dusting of dry glass powder on a steel sheet coated with a very thin oil film, and eventually by some other methods (see Figure 1).

After drying, the glass coating is fired for several minutes at temperatures ranging from $780^{\circ}$ up to $960^{\circ} \mathrm{C}$ in a furnace. During the firing the glass covering the steel melts at first, thus creating a thin glossy glass film, which prevents scale forming. Should the temperature overreach $780^{\circ} \mathrm{C}$, a reaction occurs among glass, iron and oxygen, creating a film on steel having other properties which are as follows: 


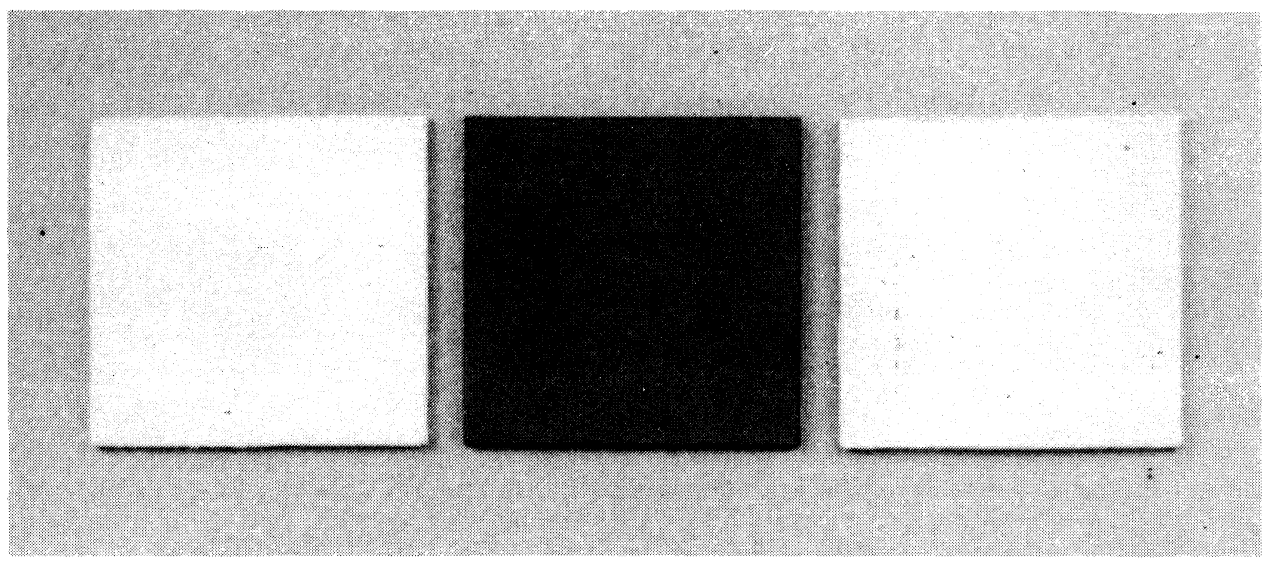

FIGURE 1 Steel substrates coated with (from the left) glass powder, ground coating and final ceramic coating.

1) The coating is dull till folded as per the amount of glass powder applied to the steel surface (see Figure 2). Due to this reason, the thickness of the coating is difficult to determine. Its colour changes from dark grey to light grey according to the firing temperature. The melting temperature of the coating is not estimated but it is higher than $1,100^{\circ} \mathrm{C}$.

2) The coating is partially ingrained in the substrates and adheres exceptionally well to steel and it cannot be removed in a simple way. The coating does not peel even during

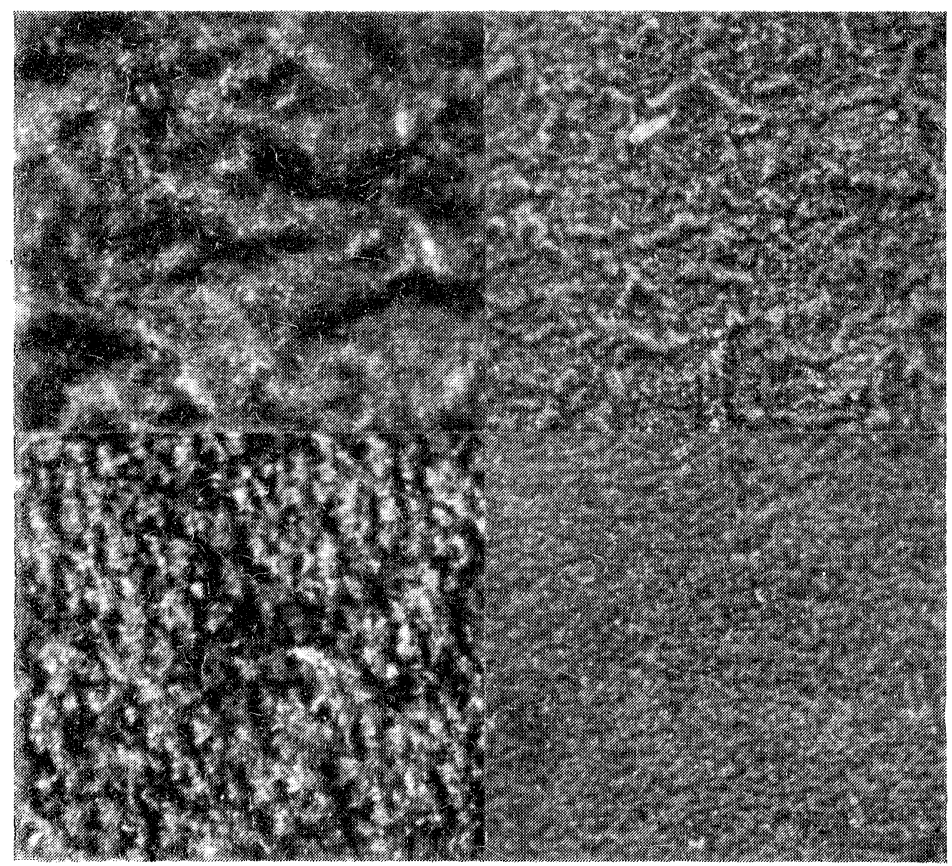

FIGURE 2 Micrographs of ground coatings (35x). 


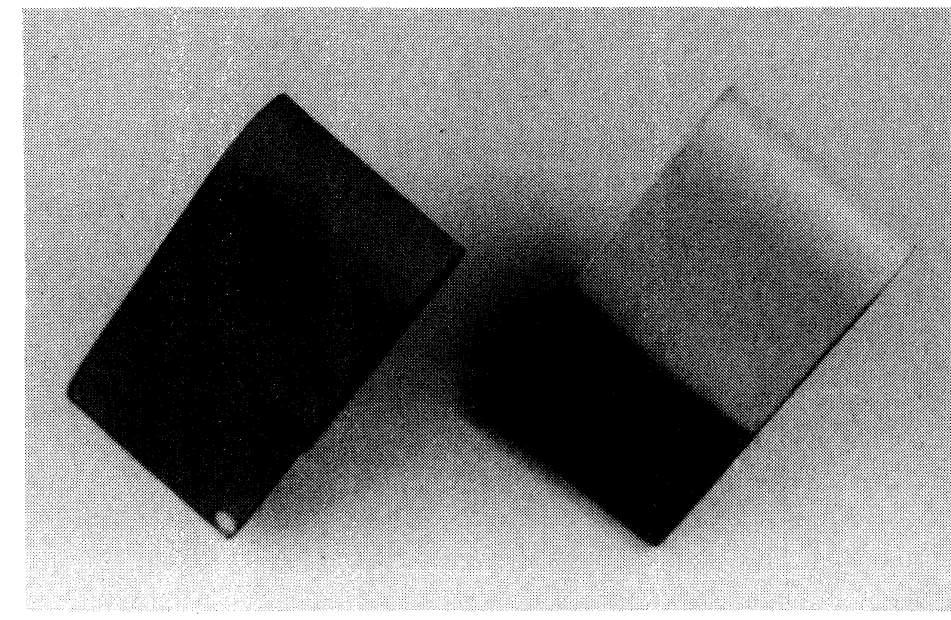

FIGURE 3 Steel sheets coated with a ground coating and also with a varnish and then bent.

sheet bending (see Figure 3). Only microscopic cracks are created but they cicatrize by refiring or local heating. The coating is resistant to damage even when subjected to quick cooling down from the temperature of $700^{\circ} \mathrm{C}$ by submersing in water.

3) The ground coating is also well resistant to some acids. For instance nitric acid did not cause any apparent changes in the coating during a period of four weeks.

4) Coated substrates can be subjected to multiple firing cycles in the air at least up to the temperature of $880^{\circ} \mathrm{C}$ without causing any peeling of the coating.

5) The coating protects steel against corrosion to a certain degree. Varnish and enamel of various kinds can be applied easily to the ground coating adhering to the surface exceptionally well (see Figure 3). Any varnish or enamel not adhering well to this coating would be discernible.

6) The electrical resistance of the coating depends on the firing temperature and the firing time, and can reach values up to $10^{9}-10^{10}$ ohms between the $0.5 \mathrm{~mm} \times 0.5 \mathrm{~mm}$ electrodes. Breakdown voltages vary between 200 up to $300 \mathrm{~V}$.

7) Should glass powder be mixed with $\mathrm{ZnO}$ powder before being applied to the substrate, a film is created after the firing which has similar properties as those of the previous case, with the exception that its electrical resistance is considerably lower and amounts to about $4 \mathrm{kohms}$ between the electrodes.

8) When firing at lower temperatures $\left(720^{\circ} \mathrm{C}\right)$, a glossy film is created. In spite of the fact that the film created by the above method shows a relatively high electric resistance, it cannot be used for applying metal films, the latter requiring another heat treatment. The coating is crystalline and during the heating a diffusion of metal occurs along the crystalline grains towards the steel core. This causes a short circuit between the steel core and the applied metal film. It is obvious that it is necessary to apply another film to the ground coating in order to prevent the above diffusion of conductive particles. Enamels are preferred which, however, permit firing temperatures below about $675^{\circ} \mathrm{C}$ only.

\subsection{Final ceramic coating}

To create the final insulating coating of the steel substrates dielectric compositions (e.g. Du Pont 9950) were applied to the ground coating by the screen printing method 


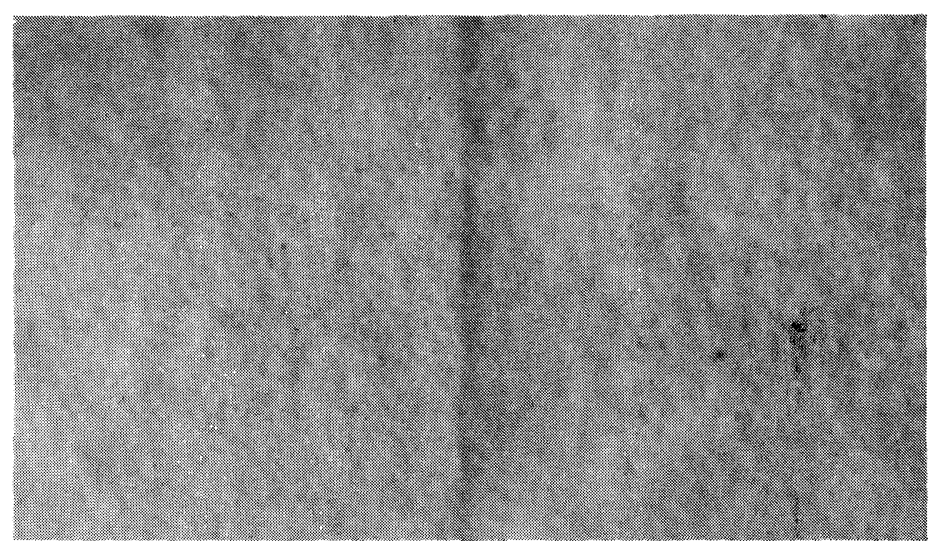

FIGURE 4 Micrograph of a final ceramic coating ( 3 and 4 films) (35x).

and then fired at $860^{\circ} \mathrm{C}$. It showed that these created coatings, having a suitable thickness, allow further firing up to $860^{\circ} \mathrm{C}$. However, it proved that the created coatings peeled at the edge of the substrate.

Due to this reaction another paste was prepared containing again EV 201 glass and $\mathrm{Al}_{2} \mathrm{O}_{3}$ powder in various ratios and liquid vehicle. This composition was printed, its film thickness being 15 microns, and then fired at peak temperature ranging from $780^{\circ}$ up to $960^{\circ} \mathrm{C}$ for $1-20$ minutes at peak. The total thickness of the coating was changed by multiple printing, varying up to $60-80$ microns.

The ceramic insulated steel substrates created have the following basic properties:

1) The coating is grey-white till white-grey in relation to the mixture proportion glass $+\mathrm{Al}_{2} \mathrm{O}_{3}$ - which can be varied from $10 \mathrm{wt} \%$ up to $100 \mathrm{wt} \%$ glass and from $0 \%$ up to $90 \mathrm{wt} \% \mathrm{Al}_{2} \mathrm{O}_{3}$. When the glass content is from $100 \mathrm{wt} \%$ up to $40 \mathrm{wt} \%$ a glossy coating is created. When the $\mathrm{Al}_{2} \mathrm{O}_{3}$ content is increased the fired coating starts to show ceramic properties. The quality and smoothness of the surface depends on the method of application. When using the screen printing method, a relief is formed by the screen, or another slightly uneven surface can be seen (see Figures 4 and 5).

2) After firing, the final coating joins the ground coating very well, so that the substrates can be heated many times at least up to $860^{\circ} \mathrm{C}$ without damaging the coating.

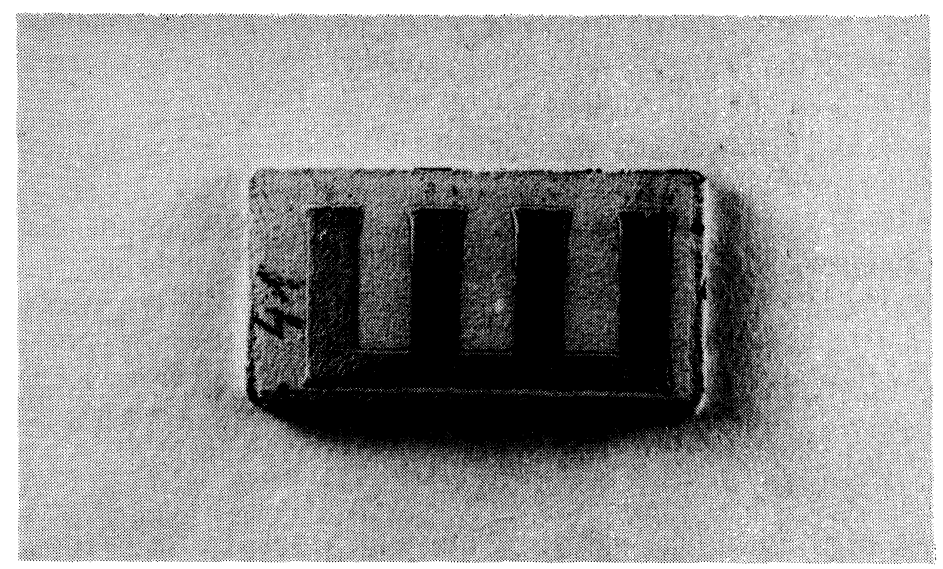

FIGURE 5 Resistor test pattern. 


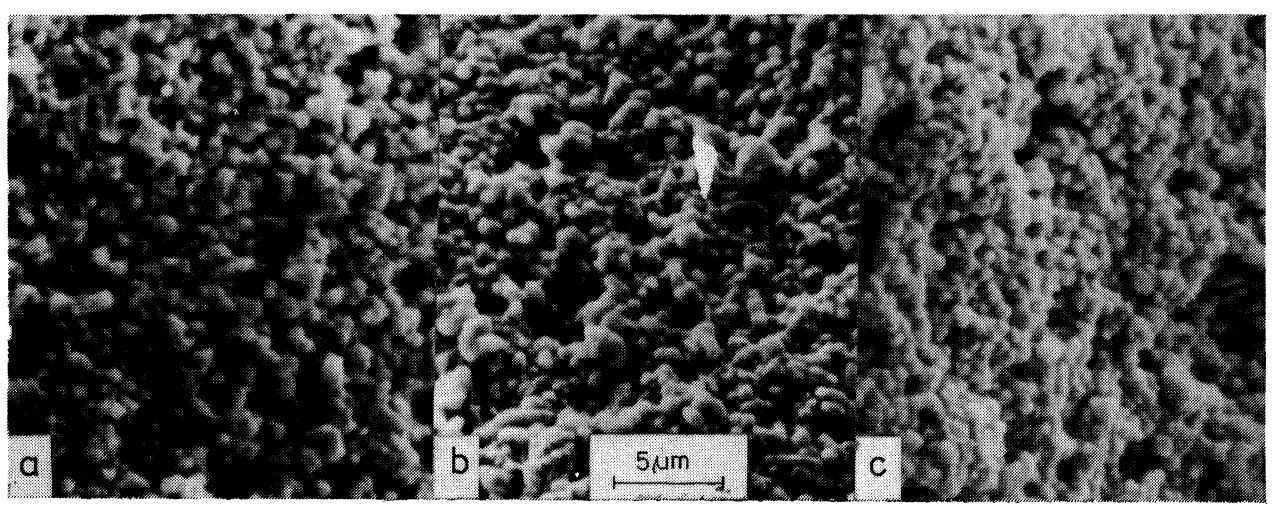

FIGURE 6 Scanning electron micrographs of final ceramic coatings. a) $15 \mathrm{wt} \%$ glass $+85 \mathrm{wt} \%$ aluminum oxide, b) $20 \mathrm{wt} \%$ glass $+80 \mathrm{wt} \%$ aluminum oxide, c) $25 \mathrm{wt} \%$ glass $+75 \mathrm{wt} \%$ aluminum oxide.

3) The electrical resistance between the $4 \mathrm{~mm} \times 3 \mathrm{~mm}$ gold pads and the steel core reaches the values up to $7.10^{12} \mathrm{ohms}$ (for two or three printed films) and it does not vary even after the refiring.

4) The breakdown voltages vary according to the number of applied films from $400 \mathrm{~V}$ for double film up to $1000 \mathrm{~V}$ for triple film.

5) During the firing process, $\mathrm{Al}_{2} \mathrm{O}_{3}$ areas are coated with glass in which $\mathrm{Al}_{2} \mathrm{O}_{3}$ solutes partially and interjoin with one another, thus creating a relatively compact coating (see Figure 6).

\section{ELECTRICAL PROPERTIES OF RESISTORS}

Some kinds of resistor compositions based on ruthenium compounds (especially Du Pont 1461 and 1411 series and our compositions marked No 11 and No 41) were selected for the preparation of thick film resistors. The resistors were printed on alumina and the above mentioned enamelled (ceramic insulated) substrates were provided by $\mathrm{Au}$ terminations, then dried and fired at peak temperatures ranging from $820^{\circ}$ up to $900^{\circ} \mathrm{C}$ for 10 minutes at peak. The total cycle time was 45 minutes. The dimensions of the resistors were $4 \mathrm{~mm} \times 2 \mathrm{~mm}$ and their dried film thickness amounted to 25-28 microns (see Figure 5). The composition containing $15 \mathrm{wt} \%$ glass and $85 \mathrm{wt} \%$ aluminum oxide was used to prepare ceramic coating.

The electrical resistance and the temperature coefficient of resistance of the prepared resistors were measured. Figure $7 \mathrm{a}$ shows the sheet resistance as a function of peak firing temperature for resistors printed on enamelled steel substrates (full lines) and on alumina substrates (dashed lines) for four resistor compositions mentioned above. The sheet resistance of the resistors printed on enamelled substrates by using DP 1461 series is about two times higher than that of the resistors printed on alumina substrates. However, the respective curves are only shifted in relation to one another (see curves 1 and $1^{\prime}$ ).

A similar behaviour was found with resistors prepared from the compositions DP 1411 and No 11 . Difference between the substrate types is approximately $25 \%$ maximum with higher resistance on alumina substrates (see curves $2-2^{\prime}$ and $3-3^{\prime}$ ). The resistors prepared from composition No 41 show a higher difference in resistance values (see curves 4 and $\left.4^{\prime}\right)$. 

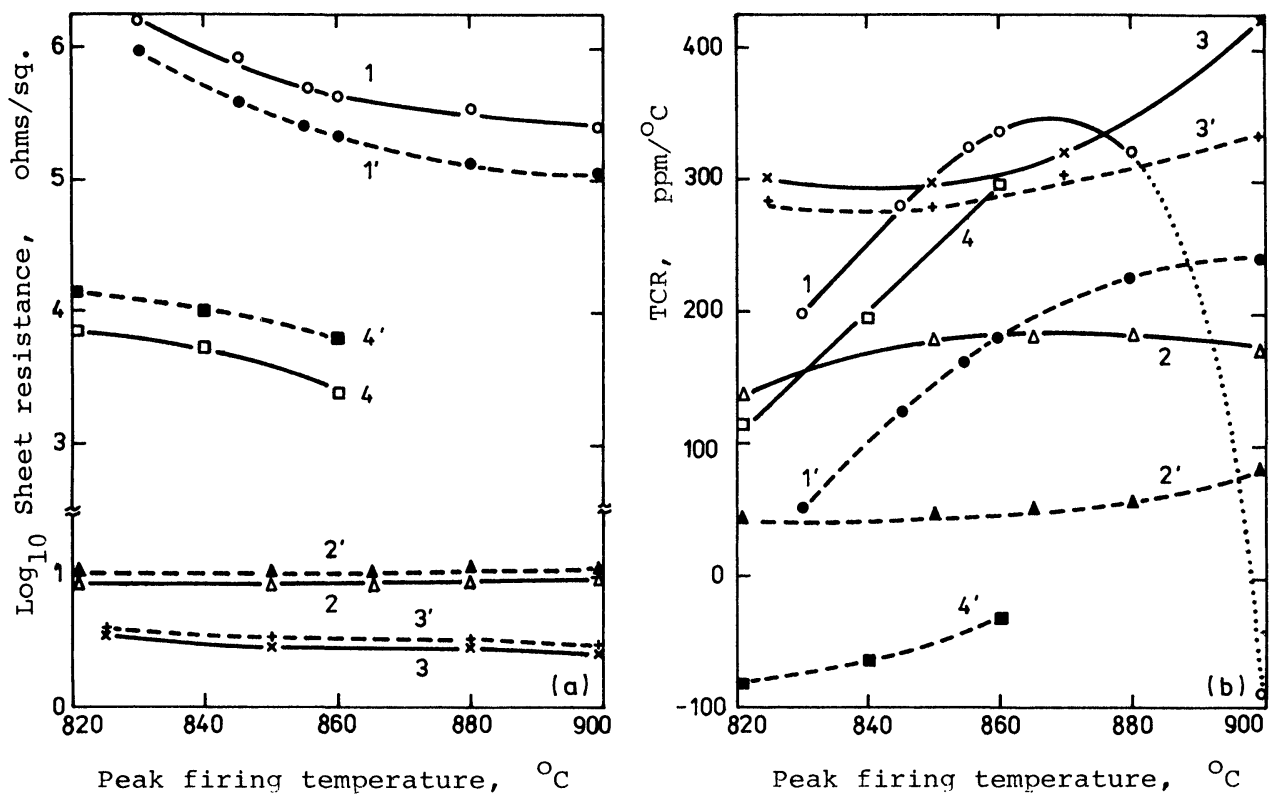

FIGURE 7 Sheet resistance (a) and TCR (b) vs. peak firing temperature for resistors screen-and-fired on enamelled steel (full lines) and alumina (dashed lines) substrates for DP 1461 and 1411 series (curves 1-1' and 2-2', resp.) and for compositions Nos 11 and 41 (curves 3-3' and 4-4', resp.).

The dependence of TCR of resistors printed onto alumina substrates (dashed lines) and of those printed onto enamelled steel substrates on the peak temperature shows that the respective curves are shifted in relation to one another. The enamelled steel substrates show more positive values (see Figure $7 \mathrm{~b}$, full lines). The extent of the shifting depends on the applied resistor composition. The TCR of 1461 resistors on enamelled substrates is higher about $+160 \mathrm{ppm} /{ }^{\circ} \mathrm{C}$ up to the peak firing temperature of $860^{\circ} \mathrm{C}$. With higher temperatures, the TCR reaches the maximum at about $870^{\circ} \mathrm{C}$, and decreases quickly down to negative values (see Figure $7 \mathrm{~b}$, curve 1). It cannot be excluded that at a high temperature a certain reaction of the resistor composition with the substrate may occur.

The TCR of DP 1411 resistors on enamelled substrates is higher, about $130 \mathrm{ppm} /{ }^{\circ} \mathrm{C}$ (see curves 2 and $2^{\prime}$ ). In the case of a very low resistor composition No 11, the difference in TCR is still lower about $25 \mathrm{ppm} /{ }^{\circ} \mathrm{C}$ (see curves 3 and $3^{\prime}$ ). A higher difference in TCR is observed for both kinds of substrates for $10 \mathrm{kohms}$ resistors.

Furthermore a long term resistor stability results. It shows that the resistance change at $150^{\circ} \mathrm{C}$ after certain time is practically the same for resistors printed on both types of substrates. In some cases the resistance stability of the resistors printed on enamelled substrates is even higher.

\section{CONCLUSION}

The performed experiments have shown that steel substrates coated with ceramic insulating coating can be prepared which are suitable for printed resistors even when applying resistor compositions designed for the use on ceramic substrates. The difference lies precisely in the fact that the resistance values are shifted towards higher or lower values in 
relation to the kind of applied resistor composition. This fact is obviously influenced by the surface state. Enamelled steel substrates laboratory prepared by us have not such a smooth surface as that of alumina substrates. The surface characteristics are influenced also by a composition of the paste (by the ratio of glass and $\mathrm{Al}_{2} \mathrm{O}_{3}$ ) applied to the ground coating. Furthermore these resistors differ from those printed on alumina substrates by their temperature coefficient of resistance which is shifted to more positive values in all the cases of used resistor compositions. Such a behaviour can be explained by higher thermal expansion coefficient of enamelled steel substrates compared to that of alumina substrates, as it has been reported in the paper. ${ }^{5}$

In order to reach a lower value of TCR, it is probably sufficient to reduce the content of components in the resistor compositions having positive TCR.

Steel substrates coated with ceramic insulating coating can be easily prepared even under laboratory conditions. It is sufficient to apply a suitable kind of glass, e.g. EV 201, and a suitable mixture of glass and $\mathrm{Al}_{2} \mathrm{O}_{3}$. The preparation of all the substrate with its intermediate ground and final coatings takes only about 20 up to 30 minutes, because neither heating nor cooling during firing cycles need to be performed slowly. The creation of the suitable ground coating on steel is the most important step for the preparation of enamelled steel substrates of the studied type.

The suggested type of enamelled steel substrates will find a good application in hybrid electronics.

\section{REFERENCES}

1. S.J. Stein, C. Huang and A.S. Gelb, "Comparison of enamelled steel substrate properties for thick film use", Proc. European Hybrid Microelectronics Conf. Ghent pp 525-538, (1979).

2. R.B. Schabacker, "Porcelained enamelled substrates for hybrid circuits and printed circuits", Proc. European Hybrid Microelectronics, Conf. Ghent pp 539-554 (1979).

3. R. Kuzel and J. Broukal, "Způsob pripravy ochranných povlaků na ocelové výrobky", Patent application PV-8362-79 (in Czech).

4. R. Kuzel and J. Broukal, "Způsob pripravy izolacnich povlaků na ocelové výrobky", Patent application PV-442-81 (in Czech).

5. A. Cattaneo, L. Pirozzi, B. Morten and M. Prudenziati, "Influence of the substrate on the electrical properties of thick film resistors", Proc. European Hybrid Microelectronics Conf. Ghent pp 123-132, (1979). 

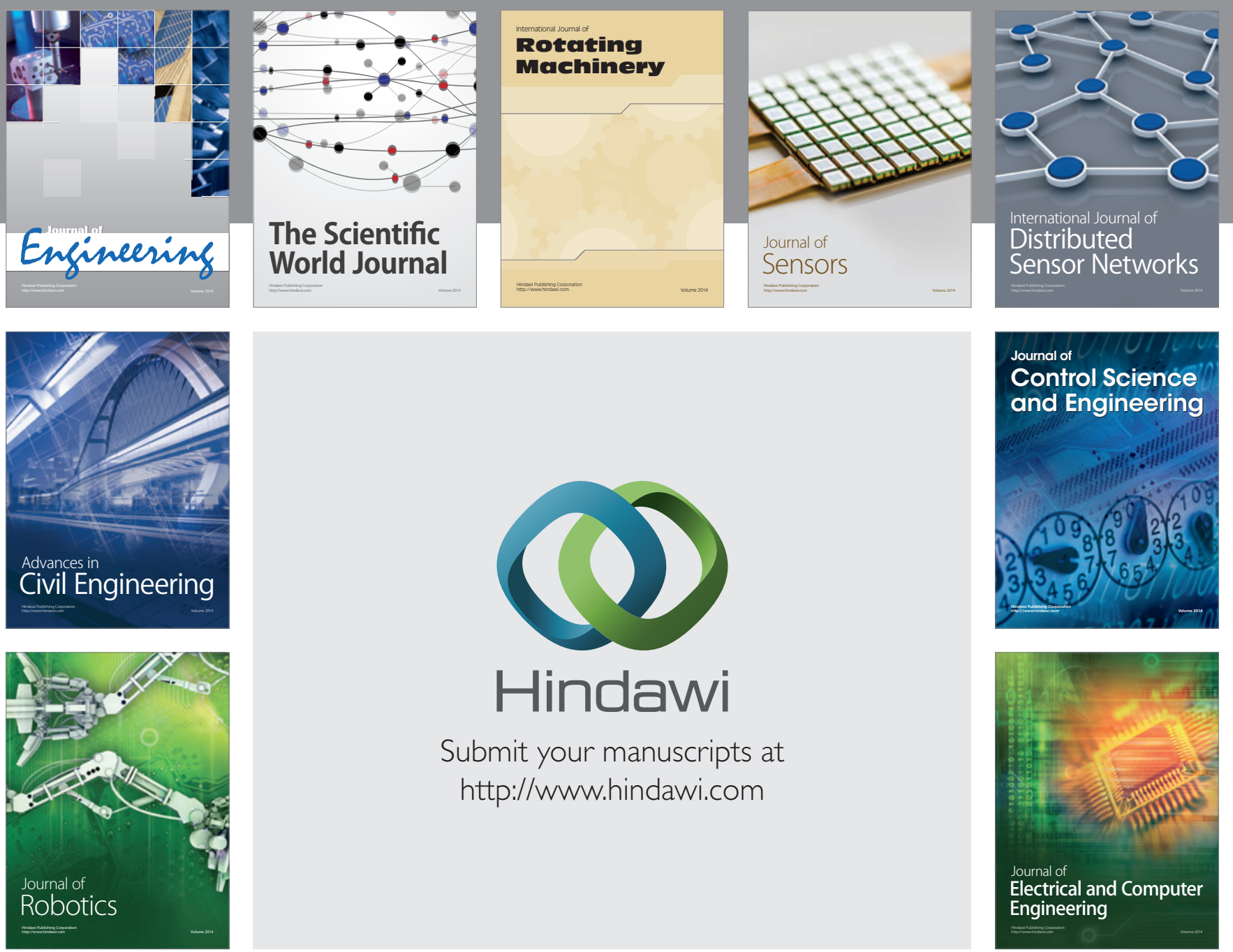

Submit your manuscripts at

http://www.hindawi.com
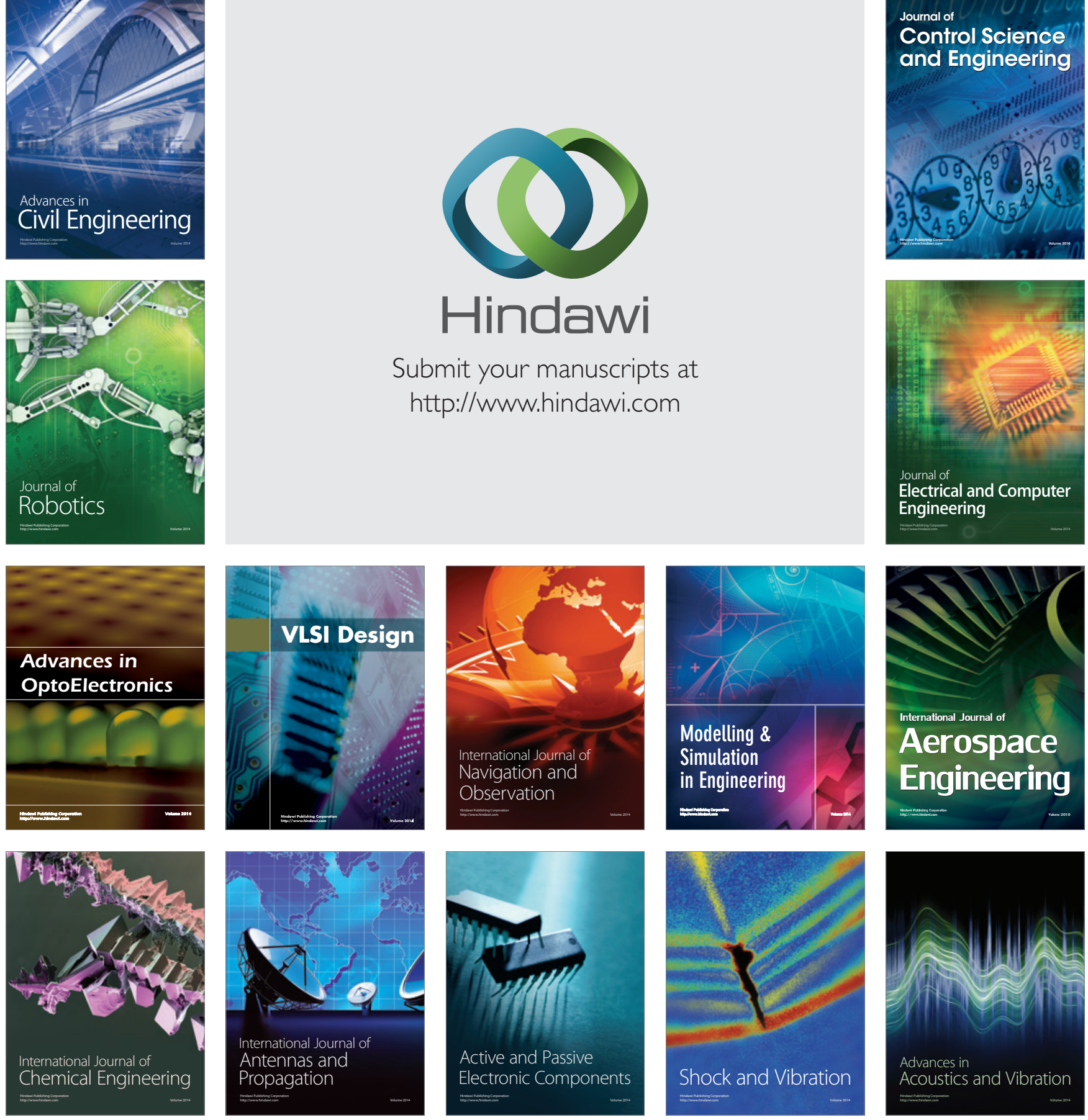